\title{
10. Expanding the deliberations about the research-policy gap: useful ideas from the literature
}

\author{
Gabriele Bammer, Lyndall Strazdins, \\ David McDonald, Helen Berry, Alison Ritter, \\ Peter Deane and Lorrae van Kerkhoff
}

\section{Introduction}

Concern is mounting nationally and globally about the wellbeing of children and young people, with governments under increasing pressure to develop effective policies. There is considerable interest in how researchers can best support policymakers in this enterprise. This chapter presents the results of a reading, discussion and writing group that examined an eclectic range of literature for insights into improving research-policy interactions. The chapter is based on evaluating our experiences in research-policy interactions against ideas generated by reading about 200 books and journal articles.

Each of us is involved in research that seeks to influence policy - in Australia, globally or both - and we have combined forces to strengthen our understanding of how to become more effective in that process. We actively traded ideas between our experiences as researchers, investigating global environmental change and food security (GB, PD), illicit drugs (AR, GB, DM), health-promoting working conditions (LS), mental health and wellbeing (HB) and global public health institutions (LvK). Some of us (AR, HB, DM) have had previous careers as public servants.

There is now a very large literature about research-policy interactions, but there have been few attempts to draw it together in any systematic way, especially in terms of marrying insights across different areas such as environment and population health. We read in both of these areas on the assumption that expanding the range of considerations would open up new ideas and issues for debate about research-policy interactions. There are many ways in which we could have proceeded. To draw on the group's strength in representing a diversity of research interests, as well as policymaking experience, we chose an expansive literature survey encompassing 
Bridging the 'Know-Do' Gap

1) how research is used to support policymaking

2) evaluating research-policy interactions

3) a range of considerations about the research enterprise, including quality, scope and capacity.

We focus particularly on the research role of providing technical support and differentiate this into two components: the extent and quality of the technical support (the amount of research information that is available and its validity), and the process through which technical support is provided. We do not explore the role of research in evaluating government policy or in providing new social theory, ideas and critique; nor do we explore debates about scientific knowledge (for example, Godfrey-Smith 2003; Jasanoff 1998; Redclift 1998). We also do not deal with insights from theories of policymaking, which highlight different aspects of a messy and complex process. Thus, we largely exclude issues of power and pressure groups, as well as opportunistic responses when policy windows open. We have dealt with these issues elsewhere (Ritter and Bammer, 2010).

We have two overall aims in this chapter. One is to present a number of interesting ideas that emerged from our reading and discussion and that could assist researchers and policymakers to improve their interactions. The second is to highlight aspects of this connection that would benefit from further investigation. We believe that there is much to be gained from research targeted at better understanding the research-policy nexus itself. The next section in this chapter provides selections from the current literature on research-policy interactions. We then deal with two significant gaps in some detail: lack of evaluation and lack of consideration of key aspects of the research enterprise.

\section{Selected literature on research-policy interactions}

Our reading identified a number of key reviews (for example, Bulmer 1986; Edwards 2001; Hanney et al. 2003; Nutley et al. 2007) and while our considerations intersect with theirs, we seek to complement rather than replicate their analyses. We also acknowledge that we will have missed key references and that the English-language literature we read-mostly from the United States, the United Kingdom, Australia and Canada - is not representative of researchpolicy interactions globally.

We found a large literature exhorting researchers to conduct investigations that are more relevant to policy concerns (for example, Edwards 2004; Gregrich 
2003), along with many papers urging researchers to pay more conscious attention to the presentation of research results, especially writing short reports tailored to policymakers, abridging results without oversimplification and taking care that they reach policymakers through targeted approaches, such as special mailings or face-to-face presentations (for example, Brownson et al. 2006; Edwards 2004; Heyman 2000; Saunders 2006; Secker 1993). We begin our considerations by examining literature that views researchers and policymakers as 'two communities' (Booth 1988), seeing the primary task of engagement as bridging these communities. We consider the different perspectives of policymakers and researchers, different kinds of interaction between these two groups, questions and check lists that aim to alert researchers to key issues relevant to influencing policy and ways of spanning the boundaries. We also look at the value of highlighting rather than glossing over the heterogeneity within each community.

\section{Different perspectives of researchers and policymakers}

The 'two-communities' approach raises awareness of the different perspectives of policymakers and researchers, which can make working together difficult. Gregrich (2003) emphasised

- different research and policy priorities, so that research does not address the most urgent questions for policymakers

- inability on each side to effectively manage uncertainties, plus lack of understanding of the limitations inherent in research and policy approaches

- inability to communicate vital information to the 'other side'

- different time cycles, so that, for example, release of research findings rarely takes into consideration the policymakers' decision-making timelines, such as budget and legislative cycles

- lack of researcher appreciation of policy funding constraints

- no current differentiation of researchers from self-interested parties seeking to influence public policy.

Heyman (2000) has taken a different approach, highlighting

- researcher emphasis on making one change at a time and holding other variables constant versus policymaker emphasis on multiple changes and horse-trading between options

- researcher emphasis on randomised controlled trials as a gold standard versus the political difficulties of running trials on social policies; voters expect 
policies to be based on the best evidence rather than experimentation, which can succeed or fail

- researcher emphasis on central tendency (such as effects of interventions on mean scores) versus policymaker emphasis on the full diversity of the effects of policy

- researcher dismissal of 'outliers' versus policymaker attraction to unusual stories that can encapsulate symbolic power and/or capture the media

- researcher emphasis on targeting for maximum benefit versus policymaker emphasis on general applicability

- researcher emphasis on long-term effectiveness versus policymaker favouring of short-term results that fit within budgetary, electoral or other politically significant cycles.

Gibson (2003a, 2003b) provided a complementary analysis to those of Gregrich and Heyman, exploring a matrix between the 'irrefutability' of the evidence and the 'immutability' of policy (Table 10.1). Changed, or new, policy is most likely when the evidence for change is strong and the political forces maintaining the existing policy are weak. Changed policy is least likely when the evidence is weak and the political forces maintaining the existing policy are strong. When the evidence for change is strong, and the political forces maintaining the existing policy are also strong, the stage is set for confrontation. Nathan and colleagues (2005) made the same point when they said '[w]here strong interests and powerful groups oppose policy direction, the evidence base for government action...needs to be substantial'.

Table 10.1 Likelihood of change

\begin{tabular}{c|l|l|l}
\hline & & \multicolumn{2}{|c}{ Irrefutability of the evidence } \\
\hline & & High & Low \\
\hline \multirow{2}{*}{$\begin{array}{c}\text { Immutability of the } \\
\text { policy }\end{array}$} & High & Confrontation & Change very unlikely \\
\cline { 2 - 4 } & Low & Change likely & No pressure for change \\
\hline
\end{tabular}

Note: The likelihood of change depends on the strength of competition between political forces seeking to maintain existing policy ('immutability of the policy') and research evidence about the need for change ('irrefutability of the evidence').

Adapted from Gibson (2003b).

Gibson (2003b:26) went on to explore the considerations that influence policymakers in such circumstances and posited five indicators of their likely responsiveness to research 
1. Responsibility - 'The extent to which the policy-making organisation is unequivocally responsible for the policy problem, either in terms of legislative requirements or precedent established by prior action.' The more responsible they are, the more likely they are to act.

2. Capacity - 'The extent to which the policy-making organisation has the capacity and power to effect change in the problem.'

3. Performance - 'The extent to which it is possible to measure the policymaking organisation's performance in relation to the policy problem.'

4. "Theatre of justification" - The extent to which performance information and other data relevant to the problem are available for public scrutiny and debate.' In other words, the more the public can see and is interested in whether or not research results are being taken into account, the more likely policymakers are to be responsive to research.

5. 'Vulnerability to the consequences of error - The extent to which there is a cost (political or economic) for policy failure. Research responsiveness will increase as these costs increase.'

Gibson also pointed out that it is simplistic to think of research being translated into policy, as if it were a process of converting words from one language to another. Instead, he argued that the process is more accurately thought of as transformation, with the policy process absorbing and reconstituting the research to meet its own goals (Gibson 2003a, 2003b).

One way to deal with the differences in perspectives between researchers and policymakers is for closer connection between them. We turn to this literature now.

\section{Connecting researchers and policymakers}

In seeking to better understand different ways in which researchers and policymakers can connect, it is useful first to present published models. Jones and Seelig (2004) provided a typology differentiating between 'engineering', 'engagement' and 'enlightenment' models of research-policy interaction. The engineering model assumes a rational process in which the role of science is to provide conclusive evidence. Researchers are the technical experts who generate a solution to the problem identified and defined by policy, without questioning or involvement in policy goals or in the way knowledge is received or implemented. (This leaves aside considerations of the limited circumstances in which research can in fact provide conclusive evidence.) An engagement model takes this one step further. Rather than just being an evidence provider, the researcher is committed to bringing the knowledge, skills and values of their 
research to influence policy. The researcher takes a more hands-on approach, seeking and building collaborative relationships with relevant policymakers, so that their input and evidence can influence policy directly. The third model - the enlightenment model - is essentially one of no engagement, in which researchers are neither service providers nor collaborators, but are focused on their particular investigative enterprise. The policy influence of their work is not managed; the research might eventually influence policy through diffusion, but intellectual independence and excellence are the priorities. As this typology demonstrates, researchers can take different stances to their interaction with policymakers. While individual researchers' approaches will not always fit neatly into one of these boxes, it is useful to understand these positions, as promoting a particular type of connection can clash with the stance of the researcher and therefore be resisted.

The 'engagement model' has gained increasing popularity, with a growing literature suggesting not only how research might influence policy, but also how policy might affect research. This literature promotes greater involvement of policymakers earlier in the research process to enhance the relevance of the research (Walter et al. 2005) and advocates close working partnerships that span the whole research process (Brownson et al. 2006). Such engagement starts with the recognition that the research-policy nexus is not an 'input-output relationship (research in and policy out)' (Edwards 2004:5), but is complex and iterative. Key tasks are to jointly define the problem and to provide ways for policymakers to gain a deep understanding of research findings. The latter can include, for example, building models that allow policymakers to examine hypothetically the consequences of different policy options through various future scenarios (Henrichs 2006).

A related literature concerns adaptive management - an influential approach in the environmental sciences that has, as yet, had little impact in the areas of health and wellbeing. While care must be taken in pulling a theorisation from one field to another - as the premises of the originating theory might not apply in the new field - adaptive management can have broad value, as it addresses the common inability for research to be able to provide conclusive evidence, especially on complex problems. It seeks to guide policymaking in conditions in which significant uncertainties remain. It emphasises learning from experience and from evolving knowledge. In other words, the aim is for policymakers to try new approaches and to continually modify them based on what happens and on new developments in research. As Cash and Moser (2000:117) pointed out for policymaking on environmental issues, '[t]he central notion of this perspective is that for environmental risks characterized by long time horizons and high levels of uncertainty and stochasticity [lacking any predictable order], effective policy should be based on adaptive, iterative, and flexible experimentation'. 
In terms of child and youth health, the area of child protection is one that could potentially benefit from an adaptive management approach. Child protection is complex and there is no clear evidence of the best ways forward. Adaptive management emphasises high levels of communication and information flow, the creation of integrated information and decision systems and a process that builds trust through participation, learning and iteration (Cash and Moser 2000). Despite its appeal, there are also significant challenges, as Kasperson (2008) has pointed out. These include the likelihood of eroding public confidence, as well as policy and research credibility, through open acknowledgment of high uncertainty or past errors. In addition, mid-course corrections can raise questions about competence.

For researchers and policymakers trying to improve their interactions, these insights raise important questions that signal the need for a shared dialogue, and that show where further research would be useful. They also help avoid simplistic thinking about what might be involved in research-policy engagement. In the next section, we provide two sets of questions to guide thinking about the interactions between researchers and policymakers.

\section{Questions and checklists}

A helpful facet of the research-policy interactions literature is sets of questions and checklists that aim to help researchers build an effective exchange with policymakers. Along with providing an analytical framework for understanding the complexities of interacting with policymakers, they provide strategies for effective connections. We present two excellent examples here.

The first is a set of questions developed by Jones and Seelig (2004), which builds on their typology presented above. We have modified the questions to use child and youth health and wellbeing as the example. The value of the questions is that they alert researchers to the political and research contexts in which they and the policymakers are operating, the extent to which research informs policy in the area of interest and the types of connections between researchers and policymakers that are standard in that area. These could help researchers tailor their efforts to achieve greater influence, as researchers will be more likely to persuade policymakers if they can: 1) demonstrate understanding of how research informs policy in a particular content area; and 2) show sensitivity to the political context in which the policymakers operate. The questions are as follows

- What does it mean to link research and policy in considerations of the health and wellbeing of children and young people? 
- In which countries is this prominent on the policy agenda? Why or why not? In which regional and global bodies is it prominent on the policy agenda? Why or why not?

- Nationally and internationally, what are the main drivers of the idea of research-informed policy on the health and wellbeing of children and young people in the early twenty-first century? What have they been in recent decades?

- Why is policy interested in this topic now and how strong is this interest? Do policymakers in the various jurisdictions have similar or different interests in this issue?

- Which model(s) (engineering, engagement or enlightenment) best describes the current research-policy relationship and expectations for this relationship?

- Is there consensus between researchers and policymakers on the best model?

- What other relationships are possible and desirable?

- Are there any risks to manage?

- Which model(s) would be optimal? Is there a preferred model? Why or why not?

Second, Court and Young (2006:88) have developed a matrix of questions and suggestions for researchers seeking to influence policy. These are presented in Table 10.2 - again adapted for the area of child and youth wellbeing.

\section{Boundary spanners and boundary organisations}

There is another literature that posits that connections between researchers and policymakers can be strengthened if this becomes a specific task for selected individuals and/or organisations. This is also one response to the question of who is responsible for feeding research into the policy mix and how. Various terms have been used to describe this task when it is undertaken by individuals, including 'boundary spanner' (Williams 2002), 'research retailer' (Lomas 1993) and 'knowledge broker' (Dobbins et al. 2009). Boundary spanners tend to work with a high degree of autonomy, are negotiators and brokers comfortable with complex, ambiguous situations and perform 'the role of "policy entrepreneur" to connect problems to solutions, and mobilize resources and effort in the search for successful outcomes' (Williams 2002:121). Detailed examples of people who have effectively filled this role are, however, rare. The chapters by Humphreys and Vines, Goldfeld and Neuhauser in this volume begin to fill this gap.

In terms of boundary organisations, Rayner (2006) has argued for new institutional forms to bring science and policy together. These should also 
include representation of broader public viewpoints. In particular, he advocated 'flexible, reflexive, and accountable institutions of representative democracy that can track the emergence of issues, and are imbued with regulatory authority to respond proportionately as new information develops' (Rayner 2006:6). He went on to say that 'if we recognize that science cannot compel public policy, the need to develop effective institutional arrangements for it to appropriately inform public policy is greater than ever' (Rayner 2006:6). Van Kerkhoff (2008) made a similar argument. The Australian Research Alliance for Children and Youth (ARACY) is an example of such a boundary organisation, with the chapter by Sanson and Stanley in this volume outlining how it operates in this capacity.

Consideration of boundaries also refocuses attention away from demarcation of different research and policy roles towards 'the blurring of boundaries' in propelling more meaningful research-policy interactions (Guston 2001:399). This line of inquiry could profitably lead into considerations of co-production of science and policy (Jasanoff 1996; Lövbrand 2007; St Clair 2006), but we do not follow it here.

\section{Adding complexity to the 'two communities'}

While the two-communities framing of the research-policy relationship alerts each 'side' to the interests and perspectives of the other, it glosses over the heterogeneity within each group. When researchers and policymakers better understand the diversity in the 'other side', they can more effectively target their interaction efforts and enhance understanding of their potential partners. For example, researchers need to understand when they can be most effective targeting politicians versus public servants, as well as whether the national, state or local level is appropriate. On the other hand, policymakers seeking to commission confidential research into politically sensitive areas could benefit from knowing that university-based researchers are likely to want to publish the results of any studies they undertake, whereas this will be less of a concern for consultancy-based researchers. We now briefly outline the different types of members in each group.

Researchers are differentiated by the settings in which they work and the motivations for their investigations. Settings include universities, publicsector think tanks, private think tanks, non-governmental organisations and consultancy firms. Researchers can also work in-house for government departments and business research and development departments. They can also have a range of motivations for their research, including being curiosity driven, in other words, pursuing knowledge for its own sake; following their 
own agendas; and undertaking research that meets the particular needs of their employers. Each of these is likely to lead to a different orientation to policymaking.

Similarly, if we look at a national level, government policymakers can be categorised as elected, appointed and career officials. In a democracy such as Australia, for example, elected officials can be further differentiated between politicians in power, those in major opposition parties and those in minor parties (who could be influential if they hold the balance of power). Appointed officials include political advisers and heads of government departments. Career officials are public servants whose position continues regardless of which government is in power. Some are deeply knowledgeable about a particular policy area, while others have more generalist and less contextualised policymaking skills. Different levels of government provide another layer of diversity in numbers, types and power of policymakers. This diversity becomes particularly significant for regional and global issues. It is also worth noting that policymakers are 'elusive as a category' (Crewe and Young 2002:5). As these authors point out, apart from those in the most senior positions, government officials often do not think of themselves as policymakers, but instead see themselves as trying to influence those higher up.

The topics discussed to this point give a flavour of the sorts of issues covered in the research-policy interactions literature. We have also highlighted one limitation, which is the lack of detailed consideration given to heterogeneity among researchers and policymakers and their respective contexts. We now move on to discuss two other sets of limitations. First, we explore the general lack of, and difficulties in, the evaluation of research-policy interactions. Second, we explore a number of aspects of research that, we suggest, need closer attention.

\section{Evaluating research-policy interactions}

We found little evidence about evaluation of the effectiveness of research support for policymaking, suggesting that there is inadequate learning about what works best, why and in which situations. We are not alone in these concerns. A wide-ranging and in-depth review of literature and case studies conducted for a UK government agency reported: 'The case studies revealed no examples of rigorous evaluation of the organisations' practices to maximise research impact. For the most part...sources base their conclusions upon self-reporting by and observation of participants in the research-practice relationship' (Nutley et al. 2003:16).

What do we mean by evaluation? A UN definition emphasises 'expected and achieved accomplishments, examining the results chain, processes, 
contextual factors and causality, in order to understand achievements or the lack thereof' (United Nations Evaluation Group 2005:5). Both process and outcomes are important. To markedly improve our understanding of researchpolicy interactions, it is important to evaluate a range of issues, including: 1) the amount and quality of the research evidence provided; 2) the processes involved in developing and implementing research support for policy decision making; 3) the utilisation of research support by people engaged in decisionmaking activity; and 4) the impact of the research support on policy activity and stakeholders, and on the researchers themselves.

In principle, evaluation can take different forms at the various stages of a research-policy interaction, serving different purposes. Formative evaluation occurs early in the process to assess if the benefits of providing research support for policy are likely to justify the expenditures of time, money and expertise required (European Commission 2001). Such evaluation contributes to the development and finetuning of the interaction, clarifying and joining up goals, resources, activities, products and hoped-for outcomes. Formative evaluation is context specific and usually provides little information that can be generalised. Summative evaluation, on the other hand, is conducted after the research-policy interaction has been operating for some time or has concluded. It provides information on what has been achieved and how. It should demonstrate how the outputs and outcomes are causally related to the activities undertaken. Summative evaluation provides information that can be used to make decisions about future research-policy interactions. For example, it can reveal whether the research quality was adequate, and whether continuing interactions should continue unchanged, continue in a different form or be terminated.

In practice, however, evaluating the effectiveness of research-policy interactions is not a simple or straightforward task. For example, if such evaluation involves researchers or research organisations that are actively seeking to make policy links, the assessment has to serve multiple goals. These include demonstrating success, process accountability, return on investment, building or maintaining credibility as well as fostering strategic planning and efforts to improve.

To use evaluation effectively for accountability, we need better understanding of the complexities of research-policy interactions, so that any evaluation can take these into account in an appropriate manner. This will also assist in enhancing learning and improving future performance. Furthermore, the increasing demands of decision makers for near to 'real-time' evaluative information provides a challenge to the evaluation profession that has, in the past, concentrated on relatively lengthy evaluation research that has frequently delivered findings too late to be of use (Rist and Stame 2006). 
Bridging the 'Know-Do' Gap

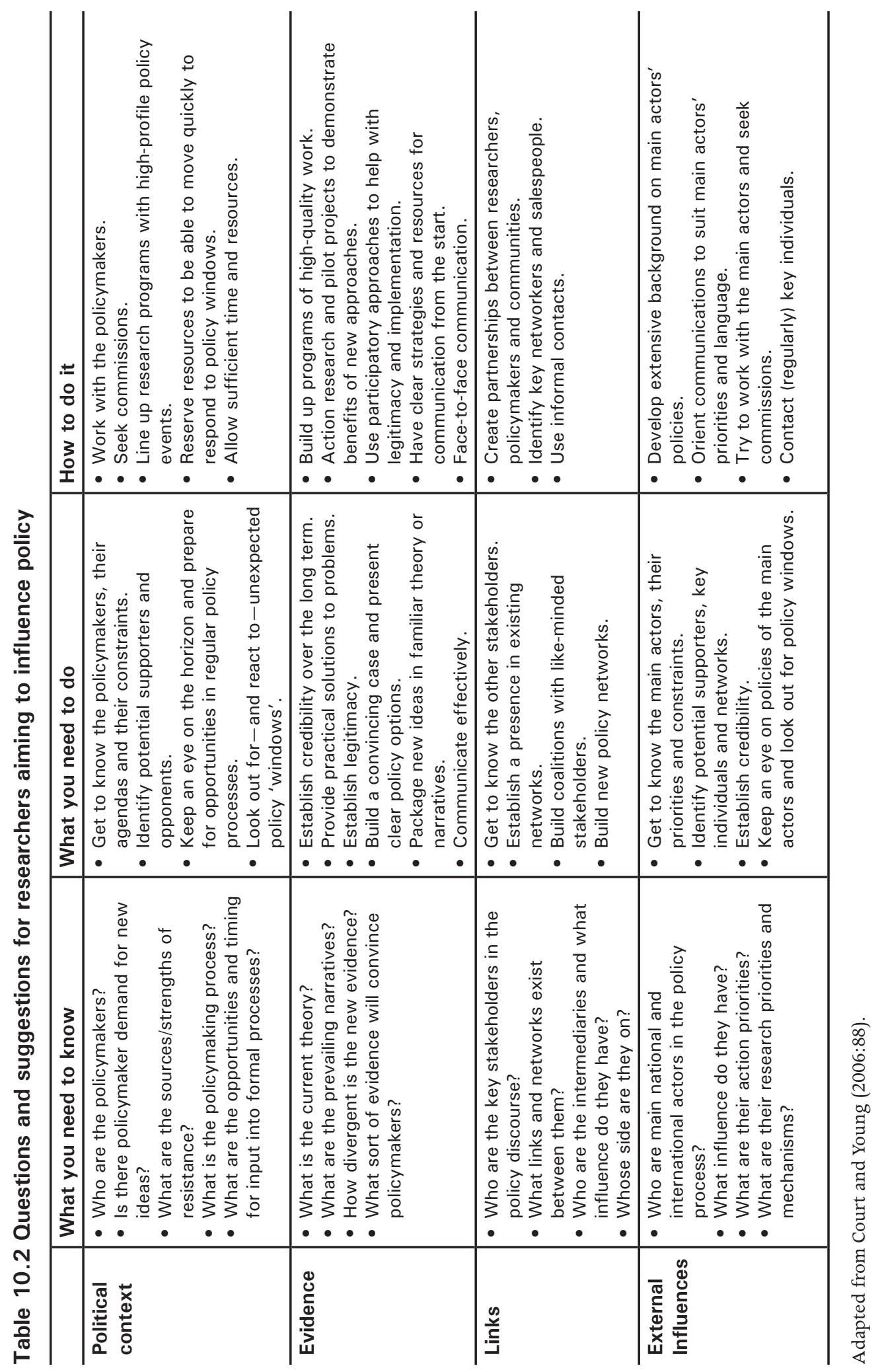




\section{Limitations of the research enterprise}

Considerations of research-policy interactions tend to focus on the process of providing research for policymaking, rather than the quality of the research, research capacity or other salient issues on the research side of the equation. In this section, we start to tease out some of these issues. We begin with the limitations of what research can offer, particularly in terms of decreasing uncertainty. We then deal with the lack of uniform quality standards and finish by considering limitations in research capacity.

\section{Research can increase rather than decrease uncertainty}

Rayner (2006) reminded us that the promise that research can point to clear-cut policy options is often illusory. While his comments focused on environmental risk, they are equally true in other areas, such as child and youth wellbeing. As he pointed out:

$[\mathrm{P}]$ olicy makers are consistently led to believe that, given time and money, scientific inquiry will reduce relevant uncertainty about environmental risk. Their scientific advisors hold out the promise that more finegrained information will clarify the nature and extent of the problem and enable policy makers to craft efficient and effective responses.

He went on to say that this disregards two factors - namely, that increased research knowledge often raises new questions leading to new uncertainties and that more knowledge can lead to more conflicting views. In both cases, the evidence base for policy becomes less rather than more secure (Rayner 2006:5).

For example, the statistics show that many abused and neglected children have mothers dependent on illicit drugs. Nevertheless, research has also shown that many of these mothers go to great lengths to shield their children from the effects of their drug use (Richter and Bammer 2000) and that drug-dependent mothers are judged more harshly by society-and themselves - than other mothers, even when their behaviour is very similar (Banwell and Bammer 2006). We also know that removing children from abusive family situations can have both beneficial and harmful effects. The more research delves into this area, the less clear the way to intervene becomes.

\section{Lack of uniform quality standards}

As more research is undertaken and as the problems addressed become more complex, requiring an array of research knowledge, it becomes harder to compile, 
let alone critically review, what is known. A streamlined systematic review process has been successfully introduced for judging medical research through the Cochrane Collaboration (n.d.) and for social, behavioural and education research through the Campbell Collaboration (n.d.). Another outstanding example comes from the environmental area where the Intergovernmental Panel on Climate Change (IPCC 2008) has a strenuous vetting process for research evidence. Such processes are, however, very expensive and are not applied uniformly to all areas of research.

This leads us to a more general discussion of criteria for judging research. In Australia, the National Health and Medical Research Council (NHMRC 2000) evaluated four dimensions: level (study design); quality (bias); relevance (applicability to policy); and strength (precision, reproducibility and attributability). Jacobs and colleagues (2005) put forward most of the same factors, as well as some additional ones. They suggested that usefulness could be judged by assessing whether researchers are asking and answering the 'right' questions, whether decision makers are able to understand the data and analyses, whether the findings are considered accurate, trustworthy and relevant to the decision that has to be made, whether the information is timely and whether the findings are sensitive to relevant constraints. Cash et al. (2003) reiterated some of these issues and gave additional emphasis to legitimacyin other words, inclusive, respectful and fair treatment of diverse stakeholder values and perspectives.

A key point here is that not all research deserves to influence policy. This is not sufficiently acknowledged when researchers are encouraged to engage with policymakers. For example, research that takes a narrowly focused, simplistic view of a complex problem, which is self-serving self-promotion or which is simply poorly conceived and executed might best be disregarded. We argue that the onus is on the research community, rather than the policy community, to effectively screen research. The processes used by the IPCC and Cochrane and Campbell Collaborations, as well as the more general criteria for judging research, provide guidance on how this can be done. (We note, however, that over-emphasis on one criterion for judging quality - such as reliance on randomised controlled trials in the case of the Cochrane Collaboration-can lead to its own problems. For other challenges raised by reviews, see Pawson 2002a, 2002b.)

\section{Limitations to research capacity}

As well as restrictions on what research can achieve in producing certainty, research capacity is also inherently limited. In his book Inquiry and Change (1990:162), Charles Lindblom contended that '[p]rofessional inquiry is a scarce 
resource even in a wealthy US, never abundant enough to permit study of all important social phenomena and problems, even if the entire adult population became social scientists'. He reminded us, more generally, that there can never be enough researchers to study all the important problems existing at any one time.

We have noted that not all research deserves to influence policy. Lindblom took this further, highlighting various research behaviours and institutional structures that limit the value of research. These include researcher difficulties in remaining open to new ideas that challenge key beliefs, hasty work because of competition, insulation through institutionalised subfields (often referred to as a silo mentality), allowing available research methods to dictate the work rather than the requirements of the problem and bypassing troublesome topics in favour of easier ones. These problems are all relevant to the field of child and youth wellbeing, where causal pathways and outcomes are complex. The temptation can be to conduct research on narrow topics and to 'de-contextualise' the investigation, ignoring the importance of particular social, cultural and familial structures. The findings of such studies can be quite misleading for policy development.

While the focus here has been mostly on Australia, it is also worth remembering that research capacity, in terms of the number of researchers, is unevenly distributed globally. As Anderson and Bammer (2005) have shown, it is greatly skewed in favour of high-income countries. For example, they report that United Nations Educational, Scientific and Cultural Organisation (UNESCO) Research and Development data (1996-2002) show that there is a median of 2618 researchers per million inhabitants in upper-income economy countries compared with 47 in low-income economy countries. (While these figures starkly illustrate the disparity, the exact numbers must be treated with caution, as UNESCO provided data for only 91 of the world's 241 countries and for many of the 91 countries some data are missing.)

Limitations in capacity raise questions about what research should be given priority, and this is relevant in both high and low-income countries.

The issue of research priorities also highlights a more practical query about which sorts of research are of value to policymakers and whether these are available to them. There is a general view that policymakers look for summaries, reviews and 'trans-disciplinary' analyses that include economic modelling, meta-analysis and an understanding of human behaviour (Davies 2004). Compelling stories that encapsulate the findings in terms of impact on an individual or family can also be very powerful. This does not, however, seem to be an area that has attracted much empirical research-Ritter's (2008) investigation of Australian 
policymakers in the area of illicit drugs is an exception - so that there could be benefit in further investigation of what policymakers need to work effectively and how easy it is for them to access.

\section{Conclusions}

The central argument of this chapter is that considerations of research-policy interactions have been too narrow and that broadening the focus raises critical questions that have yet to receive the attention they warrant. We have illustrated this by bringing together literature from the fields of environment and population health, as well as from three areas that are generally treated separately: research-policy interactions, their evaluation and considerations of research amount and quality. Gone are the days when researchers gloried in the 'practical uselessness' of their investigations (Passmore 1978). There are, however, not yet well thought through approaches to how research can best support policymaking, particularly policymaking that seeks to respond to complex social problems. The profound challenges posed by considerations of the wellbeing of children and young people highlight this need and provide a stimulus for action. Our focus here has been on both providing available knowledge to stimulate new thinking about research-policy interactions and encouraging more research, reflection and documentation of these interactions. We want to encourage others to take a broad view and to join us in examining and debating key issues of research priorities, research limitations and how researchers can best provide technical support for policy.

\section{Acknowledgments}

This chapter is based on an unpublished report written for the Global Environmental Change and Food Systems Project (<www.gecafs.org $>$ ), which was funded from the UK Natural Environment Research Council's support for that project. The work of the reading group was also supported by the Colonial Foundation Trust through the Drug Policy Modelling Program. Valuable comments on earlier drafts were provided by Doctors Polly Ericksen, John Ingram and Alice Roughley. Professor Dorothy Broom contributed to the early phase of the group's reading and discussion. 


\section{References}

Anderson, C. and Bammer, G. 2005, 'Measuring the global research environment: information science challenges for the 21st century', Sparking Synergies: Bringing research and practice together. Proceedings of the 68th American Society of Information Science and Technology Annual Meeting, Charlotte, NC, 28 October - 2 November 2005, viewed 16 May 2010, <http://eprints.rclis. org/4992/1/Anderson_Measuring.pdf>

Banwell, C. and Bammer, G. 2006, 'Maternal habits: narratives of mothering, social position and drug use', International Journal of Drug Policy, vol. 17, pp. 504-13.

Booth, T. 1988, Developing Policy Research, Gower Publishing Company, Aldershot, UK.

Brownson, R. C., Royer, C., Ewing, R. and McBride, T. D. 2006, 'Researchers and policymakers: travellers in parallel universes', American Journal of Preventive Medicine, vol. 30, no. 2, pp. 164-72.

Bulmer, M. 1986, Social Science and Social Policy, Allen \& Unwin, London.

Campbell Collaboration n.d., viewed 9 August 2007, <www. campbellcollaboration.org $>$

Cash, D. W. and Moser, S. C. 2000, 'Linking global and local scales: designing dynamic assessment and management processes', Global Environmental Change, vol. 10, no. 2, pp. 109-20.

Cash, D. W., Clark, W. C., Alcock, F., Dickson, N. M., Eckley, N., Guston, D. H., Jager, J. and Mitchell, R. B. 2003, 'Knowledge systems for sustainable development', Proceedings of the National Academy of Sciences of the United States of America, vol. 100, no. 14, pp. 8086-91.

Cochrane Collaboration n.d., viewed 9 August 2007, <www.cochrane.org>

Court, J. and Young, J. 2006, 'Bridging research and policy in international development: an analytical and practical framework', Development in Practice, vol. 16, no. 1, pp. 85-90.

Crewe, E. and Young, J. 2002, Bridging research and policy: context, evidence and links, Working Paper 173, Overseas Development Institute, London, viewed 15 May 2010, <http://www.odi.org.uk/resources/download/151.pdf>

Davies, P. 2004, 'Sociology and policy science: just in time?', The British Journal of Sociology, vol. 55, no. 3, pp. 447-50. 
Dobbins, M., Robeson, P., Ciliska, D., Hanna, S., Cameron, R., O'Mara, L., Decorby, K. and Mercer, S. 2009, 'A description of a knowledge broker role implemented as part of a randomized controlled trial evaluating three knowledge translation strategies', Implementation Science, vol. 4, <http:// www.implementationscience.com/content/4/1/23>

Edwards, M. 2001, Social Policy, Public Policy: From problem to practice, Allen \& Unwin, Crows Nest, NSW.

Edwards, M. 2004, Social science research and public policy: narrowing the divide, Occasional Paper 2/2004, Academy of the Social Sciences in Australia, Canberra, viewed 16 May 2010, <http://www.assa.edu.au/publications/ occasional_papers/2004_No2.php>

European Commission 2001, Ex Ante Evaluation: A practical guide for preparing proposals for expenditure programmes, European Commission, Brussels, viewed 16 May 2010, <http://ec.europa.eu/budget/library/documents/ evaluation/guides/ex_ante_guide_2001_en.pdf>

Gibson, B. 2003a, From transfer to transformation: rethinking the relationship between research and policy, PhD Thesis, The Australian National University, Canberra, viewed 1 August 2008, <http:/thesis.anu.edu.au/uploads/ approved/adt-ANU20040528.165124/public/02whole.pdf $>$

Gibson, B. 2003b, 'Beyond "two communities"', in V. Lin and B. Gibson (eds), Evidence-Based Health Policy. Problems and possibilities, Oxford University Press, UK, pp. 18-30.

Godfrey-Smith, P. 2003, Theory and Reality: An introduction to the philosophy of science, University of Chicago Press, Ill.

Gregrich, R. J. 2003, 'A note to researchers: communicating science to policy makers and practitioners', Journal of Substance Abuse Treatment, vol. 25, no. 3, pp. 233-7.

Guston, D. 2001, 'Boundary organizations in environmental policy and science: an introduction', Science, Technology and Human Values, vol. 26, no. 4, pp. 399-408.

Hanney, S., Gonzalez-Block, M., Buxton, M. J. and Kogan, M. 2003, 'The utilisation of health research in policy-making: concepts, examples and methods of assessment', Health Research Policy and Systems, vol. 1, no. 2.

Henrichs, T. 2006, On the role of scenarios in GECAFS decision-support, GECAFS Working Paper 4, Global Environmental Change and Food 
Systems, Wallingford, UK, viewed 13 February 2007, <http://www.gecafs. org/publications/Publications/GECAFS_Working_Paper_4_Henrichs_ August_2006.pdf>

Heyman, S. J. 2000, 'Health and social policy', in L. F. Berkman and I. Kawachi (eds), Social Epidemiology, Oxford University Press, New York, pp. 368-82.

Intergovernmental Panel on Climate Change (IPCC) 2008, 'Procedures for the preparation, review, acceptance, adoption, approval and publication of IPCC reports', Appendix A to the Principles Governing IPCC Work, Intergovernmental Panel on Climate Change, Geneva, viewed 18 May 2010, $<$ http://www.ipcc.ch/pdf/ipcc-principles/ipcc-principles-appendix-a.pdf>

Jacobs, K., Garfin, G. and Lenart, M. 2005, 'More than just talk: connecting science and decisionmaking', Environment: Science and Policy for Sustainable Development, vol. 47, no. 9, pp. 6-21.

Jasanoff, S. 1996, 'Beyond epistemology: relativism and engagement in the politics of science', Social Studies of Science, vol. 26, no. 2, pp. 393-418.

Jasanoff, S. 1998, 'Coming of age in science and technology studies', Science Communication, vol. 20, no. 1, pp. 91-8.

Jones, A. and Seelig, T. 2004, Understanding and enhancing research-policy linkages in Australian housing: a discussion paper, Australian Housing and Urban Research Institute, Brisbane, viewed 13 February 2007, < http://www. ahuri.edu.au/publications/download.asp?ContentID=20216_pp>

Kasperson, R. E. 2008, 'Coping with deep uncertainty: challenges for environmental assessment and decision making', in G. Bammer and M. Smithson (eds), Uncertainty and Risk: Multidisciplinary perspectives, Earthscan, London, pp. 337-47, [extracted in R. E. Kasperson 2008, 'Coping with deep uncertainty', Integration Insights, no. 9 (June), viewed 19 May 2010, <http://i2s.anu.edu.au/sites/default/files/integration-insights/ integration-insight_9.pdf $>$ ].

Lindblom, C. E. 1990, Inquiry and Change. The troubled attempt to understand and shape society, Yale University Press/Russell Sage, New York.

Lomas, J. 1993, 'Retailing research: increasing the role of evidence in clinical services for childbirth', Milbank Quarterly, vol. 71, no. 3, pp. 439-75.

Lövbrand, E. 2007, 'Pure science or policy involvement? Ambiguous boundarywork for Swedish carbon cycle science', Environmental Science and Policy, vol. 10, no. 1, pp. 39-47. 
Bridging the 'Know-Do' Gap

Nathan, S. A., Develin, E., Grove, N. and Zwi, A. B. 2005, 'An Australian childhood obesity summit: the role of data and evidence in "public" policy making', Australia \& New Zealand Health Policy, vol. 2:17, viewed 11 February 2007, <http://www.anzhealthpolicy.com/content/pdf/1743-84622-17.pdf>

National Health and Medical Research Council (NHMRC) 2000, How to Use the Evidence: Assessment and application of scientific evidence, Handbook Series on Preparing Clinical Practice Guidelines, National Health and Medical Research Council, Canberra, viewed 18 May 2010, <http://www.nhmrc.gov. au/_files_nhmrc/file/publications/synopses/cp69.pdf $>$

Nutley, S., Percy-Smith, J. and Solesbury, W. 2003, 'Models of research impact: a cross-sector review of literature and practice', Building Effective Literature No. 4, Learning and Skills Research Centre, London, viewed 18 May 2010, $<$ https://crm.lsnlearning.org.uk/user/order.aspx?code $=031418>$

Nutley, S. M., Walter, I. and Davies, H. T. O. 2007, Using Evidence: How research can inform public services, Policy Press, Bristol.

Passmore, J. 1978, Science and Its Critics, Duckworth, London.

Pawson, R. 2002a, 'Evidence-based policy: in search of a method', Evaluation, vol. 8, no. 2, pp. 157-81.

Pawson, R. 2002b, 'Evidence-based policy: the promise of "realist synthesis", Evaluation, vol. 8, no. 3, pp. 340-58.

Rayner, S. 2006, 'What drives environmental policy?', Global Environmental Change, vol. 16, no. 1, pp. 4-6.

Redclift, M. 1998, 'Dances with wolves? Interdisciplinary research on the global environment', Global Environmental Change: Human and Policy Dimensions, vol. 8, no. 3, pp. 177-82.

Richter, K. and Bammer, G. 2000, 'A hierarchy of strategies heroin-using mothers employ to reduce harm to their children', Journal of Substance Abuse Treatment, vol. 19, pp. 403-13.

Rist, R. C. and Stame, N. (eds) 2006, From Studies to Streams: Managing evaluative systems, Transaction Publishers, NJ.

Ritter, A. 2008, 'How do drug policy makers access research evidence?', International Journal of Drug Policy, vol. 20, no. 1, pp. 70-5.

Ritter, A. and Bammer, G. 2010, 'Models of policy-making and their relevance for drug research', Drug and Alcohol Review, vol. 29, no. 4, pp. 352-7. 
Saunders, P. 2006, 'Social science and public policy: connecting the ivory tower to the corridors of power', Dialogue, vol. 25, no. 2, pp. 70-4.

Secker, A. 1993, 'The policy-research interface: an insider's view', Addiction 88 (Supplement), pp. 115S-20S.

St Clair, A. 2006, 'Global poverty: the co-production of knowledge and politics', Global Social Policy, vol. 6, no. 1, pp. 57-77.

United Nations Evaluation Group 2005, Norms for Evaluation in the UN System, United Nations Evaluation Group, New York, viewed 16 May 2010, < http:// www.uneval.org/papersandpubs/documentdetail.jsp?doc_id=21>

van Kerkhoff, L. 2008, Making a Difference: Science, action and integrated environmental research, Sense Publishers, Rotterdam.

Walter, I., Nutley, S. and Davies, H. 2005, 'What works to promote evidencebased practice', Evidence \& Policy, vol. 1, no. 3, pp. 335-64.

Williams, P. 2002, 'The competent boundary spanner', Public Administration, vol. 80, no. 1, pp. 103-24. 